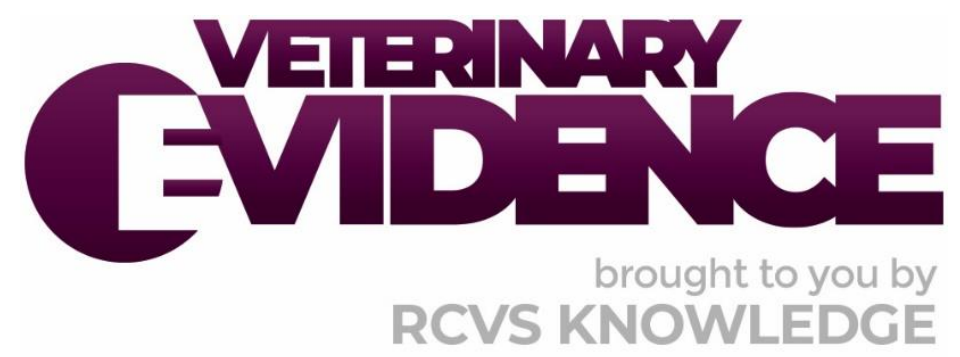

\title{
In dogs undergoing elective procedures is medetomidine superior to acepromazine when used as a premedication?
}

\author{
A Knowledge Summary by
}

Rebecca Littlehales BVSc MRCVS ${ }^{1^{*}}$

\footnotetext{
${ }^{1}$ University of Liverpool, Chester High Road, Neston, CH64 7TE

*Corresponding Author (beckylittlehales@gmail.com)
}

ISSN: 2396-9776

Published: 02 Dec 2020

in: The Veterinary Evidence journal Vol 5, Issue 4

DOI: $10.18849 /$ VE.V5I4.318

Reviewed by: Jodie Hughes (BVSc CertAVP(VA) FHEA Dip.ECVAA MRCVS) and William McFadzean (BVetMed CertAVP(VA) DipECVAA MRCVS)

Next Review Date: 23 Apr 2022 


\section{KNOWLEDGE SUMMARY}

\section{PICO question}

In dogs undergoing elective procedures does the use of medetomidine during premedication result in an increase in anaesthetic complication rates, when compared to acepromazine?

\section{Clinical bottom line}

\section{Category of research question}

Treatment

\section{The number and type of study designs reviewed}

Four papers were critically reviewed, all of which were randomised controlled trials

\section{Strength of evidence}

Strong

\section{Outcomes reported}

There were some statistically significant differences between using medetomidine and acepromazine as premedications in the outcomes measured, but as the clinical parameters including blood pressure were still within acceptable clinical limits, the clinical benefits of these findings remain undetermined. There is also evidence to suggest that patients premedicated with medetomidine have less of a perioperative stress response than those receiving acepromazine, but in addition may have increased risk of cardiac conduction disturbances, but the clinical importance of these findings is also unknown

\section{Conclusion}

The overall findings showed that either drug can be used as a suitable premedication, but the differences in pain score postoperatively shown in one small study mean that due to its poor analgesic properties it is recommended when using acepromazine instead of medetomidine, that additional analgesia should be given to reduce postoperative pain for better animal welfare

\section{How to apply this evidence in practice}

The application of evidence into practice should take into account multiple factors, not limited to: individual clinical expertise, patient's circumstances and owners' values, country, location or clinic where you work, the individual case in front of you, the availability of therapies and resources.

Knowledge Summaries are a resource to help reinforce or inform decision making. They do not override the responsibility or judgement of the practitioner to do what is best for the animal in their care. 


\section{Clinical Scenario}

Premedications are often used in anaesthetic protocols for dogs undergoing elective procedures, with acepromazine and medetomidine being commonly used in combination with other drugs. These two drugs belong to different classes of anaesthetic drugs, with acepromazine being a phenothiazine whilst medetomidine is an alpha-2 adrenergic receptor agonist. This summary aims to determine if there are any differences in anaesthetic complication rates between these two drugs, so that veterinary surgeons in practice are more informed on which would be best to use in their anaesthetic protocols for the best patient outcome.

\section{The evidence}

Four blinded controlled trials (Grint et al., 2010; Väisänen et al., 2002; Väisänen et al., 2005; and Wamaitha et al., 2019) were found to be relevant to the PICO question, which have strong study designs. The Wamaitha et al. (2019) study compared the two drugs when used as a premedication in combination with an induction using ketamine and propofol. The outcomes measured in the study that were relevant to the PICO question were postoperative pain scoring and smoothness of recovery based on time to standing and whether they had tremors when recovering, and post induction apnoea. The Grint et al. (2010) study provided a larger, more representative sample size and compared the two drugs when used in combination with buprenorphine as a premedication. The outcomes measured in this study were more based around cardiopulmonary parameters as a measure of anaesthetic complications, which were considered less in the Wamaitha et al. (2019) study. The two studies by Väisänen et al. (2002 \& 2005) were conducted concurrently using the same study design, one (2002) to compare the perioperative stress response between acepromazine and medetomidine as a premedication based on anaesthesia monitoring data, blood hormone concentrations, heart rates and mean arterial pressure and assessment of pain and distress. The other study (2005), compares the electrocardiography data of the same cohort focusing on heart rate, cardiac conduction disturbances and heartbeat variability data.

\section{Summary of the evidence}

Grint et al. (2010)

\begin{tabular}{|c|c|}
\hline Population: & $\begin{array}{l}\text { Dogs were enrolled in the study at the University of Liverpool's Small } \\
\text { Animal Hospital in a 2-year period who were undergoing routine } \\
\text { surgical or diagnostic procedures that involved only a mild to } \\
\text { moderate stimulus such as neutering, arthroscopy, endoscopy, } \\
\text { radiography and other similar minor procedures. Only dogs with an } \\
\text { American Society of Anaestheologists (ASA) status of } 1 \text { (healthy) or } 2 \\
\text { (mild systemic disease) were included in the study. }\end{array}$ \\
\hline Sample size: & $\begin{array}{l}90 \text { dogs (two dogs from Group } 1 \text { were lost so were not analysed, and } \\
\text { no explanation is given for this) }\end{array}$ \\
\hline Intervention details: & $\begin{array}{l}\text { The dogs were randomly assigned (by block randomisation and } \\
\text { sealed envelopes) to one of three groups. } \\
\text { - Group } 1 \text { ( } 28 \text { dogs) were given acepromazine }(0.03 \mathrm{mg} / \mathrm{kg} \text { ) } \\
\text { and buprenorphine }(0.02 \mathrm{mg} / \mathrm{kg} \text { ) intramuscularly. } \\
\text { Group } 2 \text { ( } 30 \text { dogs) were given medetomidine }(5 \mathrm{\mu g} / \mathrm{kg} \text { ) and } \\
\text { buprenorphine }(0.02 \mathrm{mg} / \mathrm{kg}) \text { intramuscularly. } \\
\text { - Group } 3 \text { ( } 30 \text { dogs) were given medetomidine }(10 \mu \mathrm{g} / \mathrm{kg}) \text { and } \\
\text { buprenorphine }(0.02 \mathrm{mg} / \mathrm{kg}) \text { intramuscularly. } \\
\text { Experimental procedure: } \\
\text { Before administration of any premedications, a full clinical } \\
\text { examination was performed, and sedation score was } \\
\text { recorded for each dog. }\end{array}$ \\
\hline
\end{tabular}




\begin{tabular}{|c|c|}
\hline & 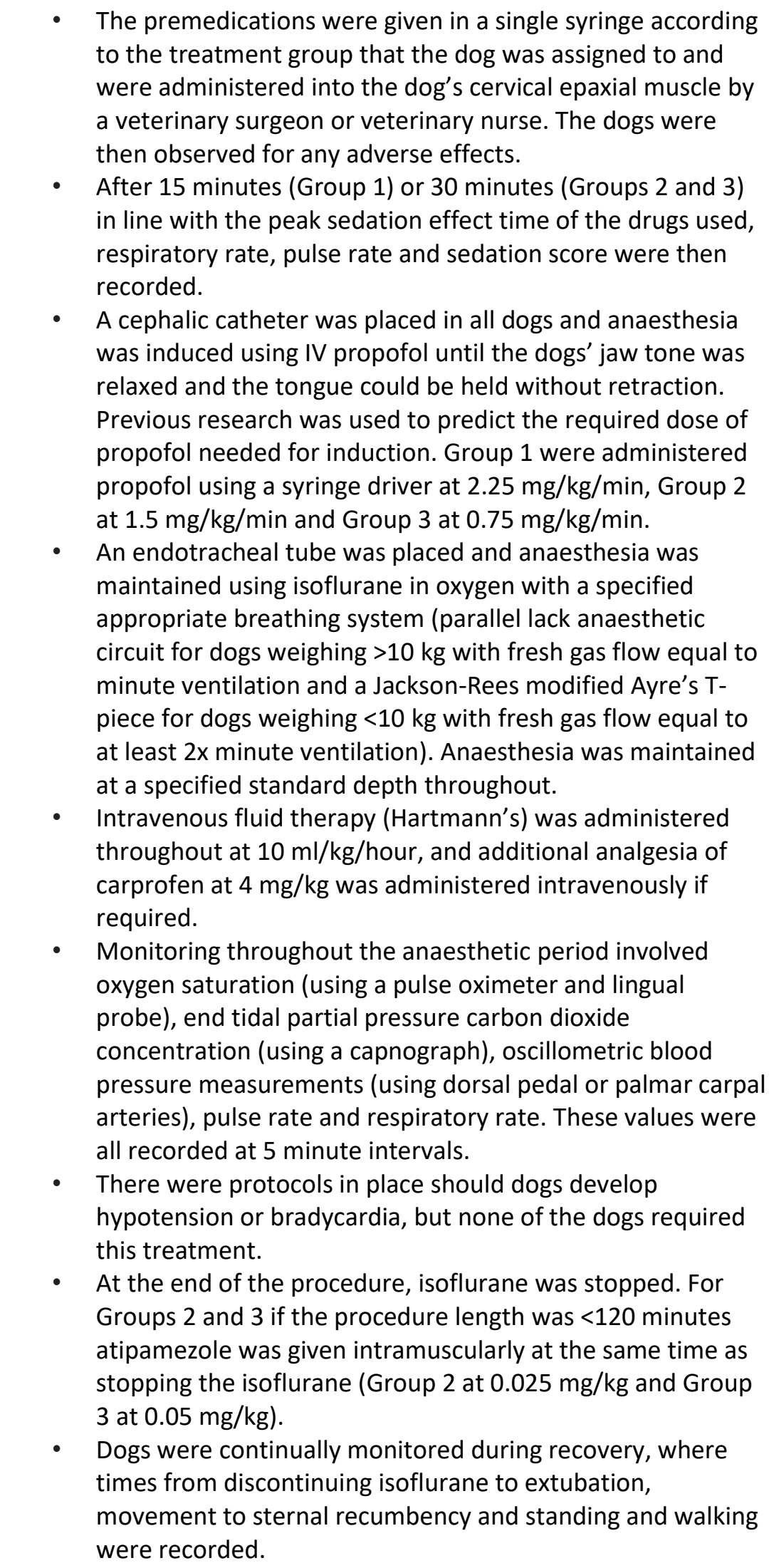 \\
\hline Study design: & Randomised, blinded, controlled trial \\
\hline Outcome studied: & $\begin{array}{l}\text { - Sedation scores } \\
\text { - Median dose of propofol used } \\
\text { - Mean vaporiser setting }\end{array}$ \\
\hline
\end{tabular}




\begin{tabular}{|c|c|}
\hline & $\begin{array}{l}\text { - } \text { Duration of anaesthesia } \\
\text { - } \text { Adverse effects post premedication } \\
\text { - Mean, diastolic and systolic blood pressure } \\
\text { - Heart and respiratory rates } \\
\text { - Mean end tidal partial pressure of carbon dioxide } \\
\text { - Oxygen saturation } \\
\text { - Time from isoflurane discontinuation to extubation, moving } \\
\quad \text { to sternal recumbency, standing and walking }\end{array}$ \\
\hline $\begin{array}{l}\text { Main findings: } \\
\text { (relevant to PICO question): }\end{array}$ & 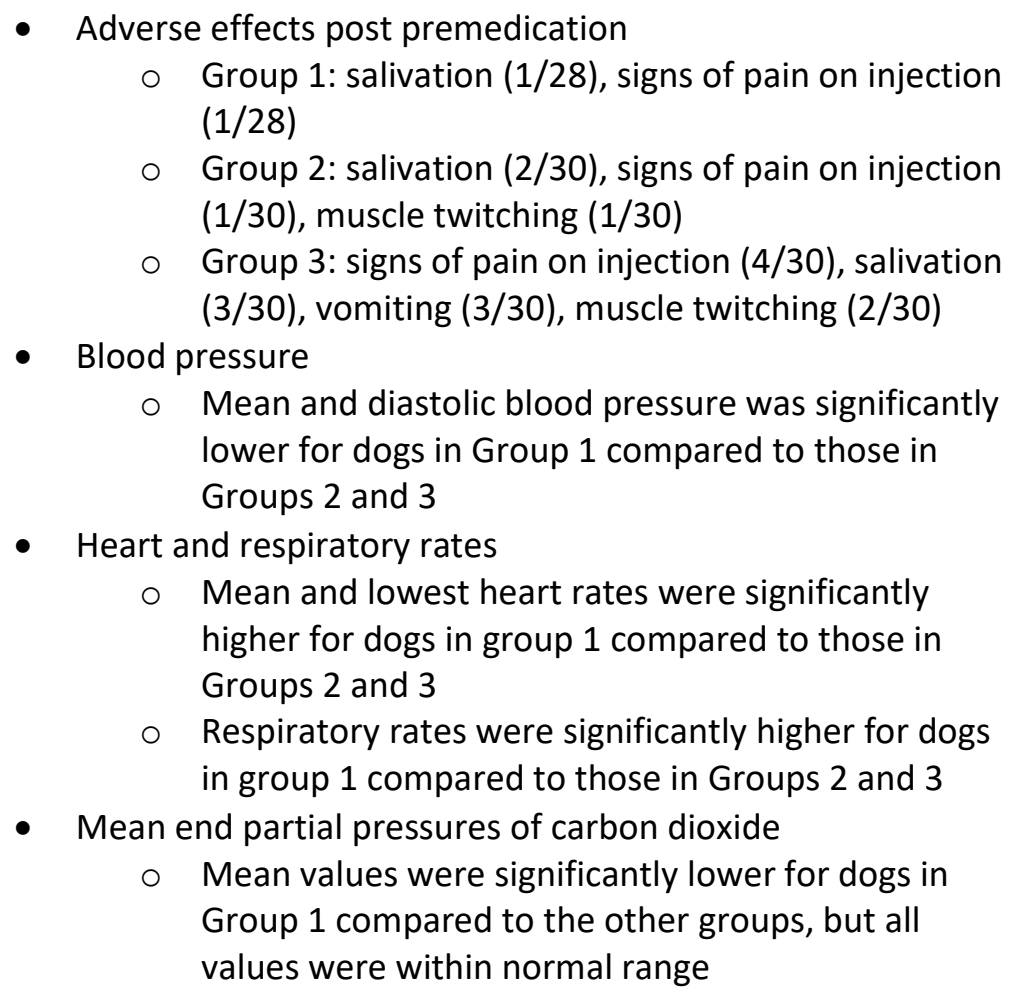 \\
\hline Limitations: & $\begin{array}{l}\text { - No record of how dogs were assessed as to whether they } \\
\text { needed additional analgesia, or how many of the dogs were } \\
\text { given carprofen as a treatment for this. } \\
\text { - The difference in the amounts of propofol and isoflurane } \\
\text { administered depending on the group may have confounded } \\
\text { the mean arterial pressure values. } \\
\text { - Tissue perfusion was not measured which may have helped } \\
\text { to explain the clinical significance of the differences in mean } \\
\text { arterial blood pressures. } \\
\text { - The dose of medetomidine used in Group } 2 \text { is lower than the } \\
\text { licenced dose range as stated by the datasheet, so at this } \\
\text { dose it used off-licence. } \\
\text { - There are two dogs' data which was not analysed as it was } \\
\text { lost and no explanation is given for this. }\end{array}$ \\
\hline
\end{tabular}

Väisänen et al. (2002)

Population: Dogs that underwent routine elective ovariohysterectomy at Helsinki University Veterinary Teaching Hospital between January and August 2000. Inclusion criteria required the dogs to have a good 


\begin{tabular}{|c|c|}
\hline & $\begin{array}{l}\text { body condition score, weigh between } 15 \text { and } 40 \mathrm{~kg} \text {, be } 2-7 \text { years old } \\
\text { and not on any medications. Brachycephalic and Greyhound-type } \\
\text { breeds were excluded. The dogs were determined to be in good } \\
\text { health based on a thorough clinical examination, and haematology } \\
\text { and biochemistry blood analysis. The age and body weights of the } \\
\text { dogs in the two different groups did not differ significantly. }\end{array}$ \\
\hline Sample size: & $\begin{array}{l}42 \text { dogs (this was initially } 44 \text { dogs, but two dogs were omitted in the } \\
\text { results due to technical difficulties) }\end{array}$ \\
\hline Intervention details: & 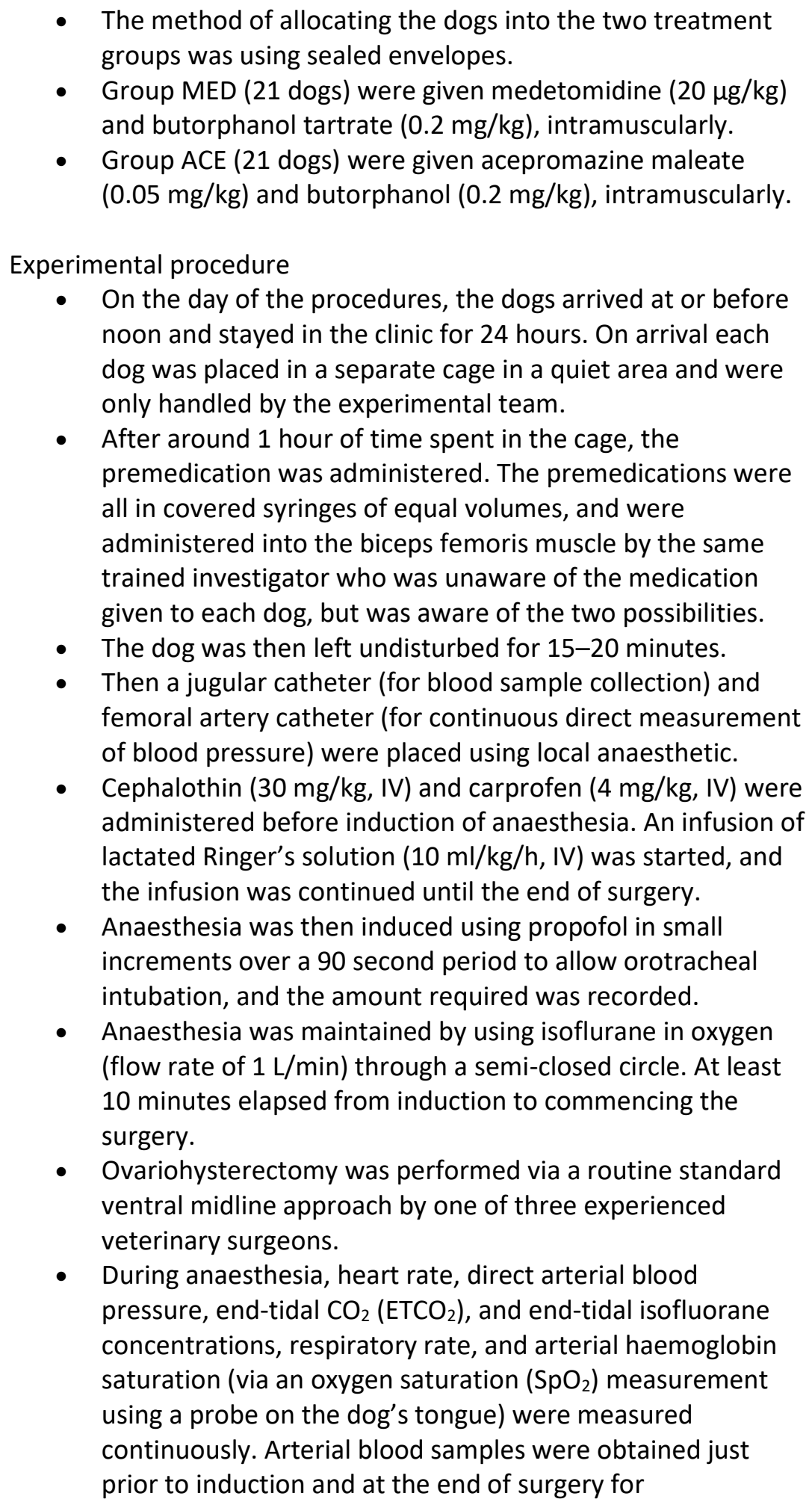 \\
\hline
\end{tabular}




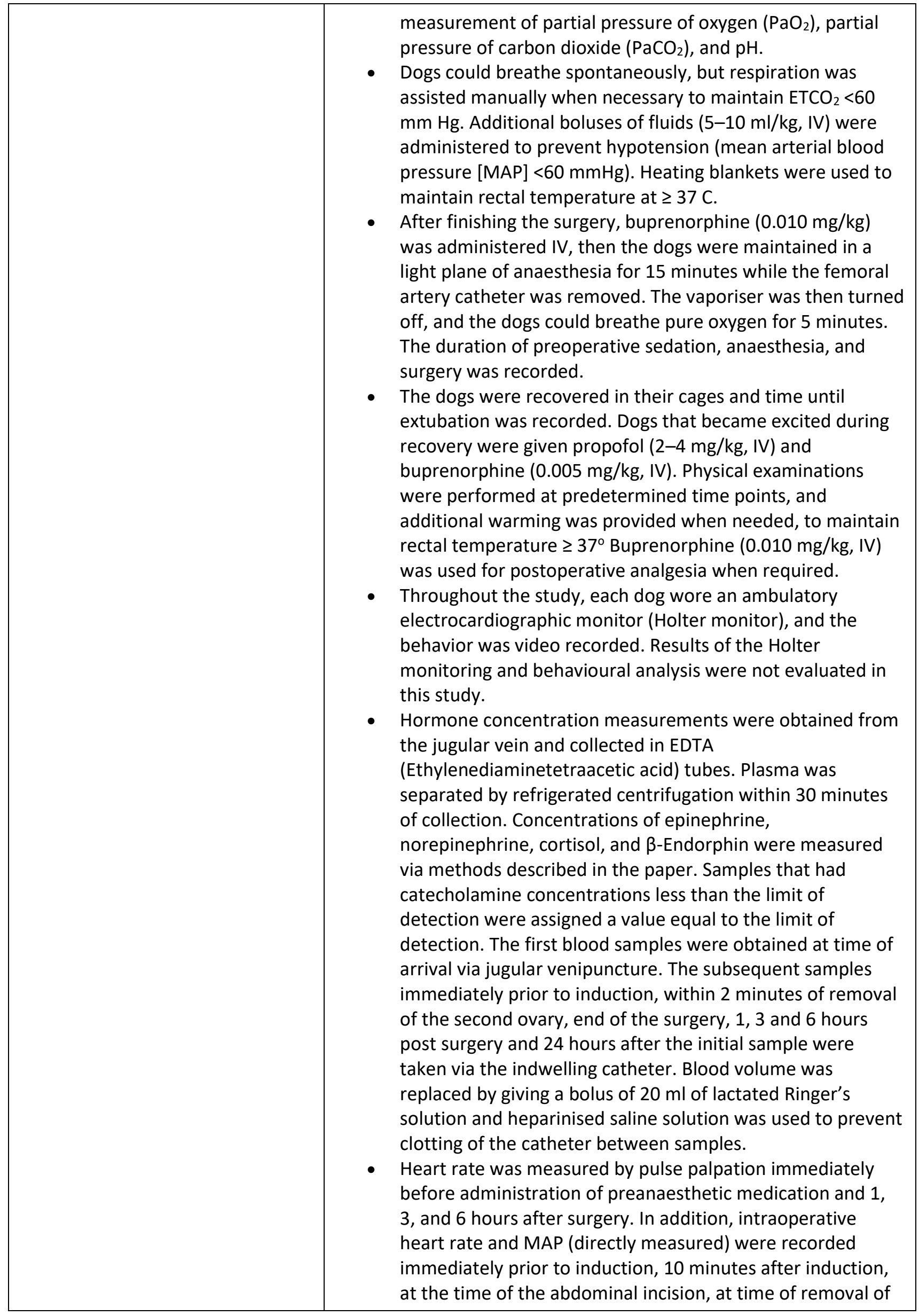




\begin{tabular}{|c|c|}
\hline & $\begin{array}{l}\text { each ovary, during closure of the incision, and at the end of } \\
\text { surgery. } \\
\text { Response of each dog to handling was recorded during the } \\
\text { entire perioperative period. Sedation and pain and distress } \\
\text { scores were determined immediately before administration } \\
\text { of preanaesthetic medication and after surgery at the same } \\
\text { times as collection of blood samples for hormonal analysis. } \\
\text { Assessments were performed for each dog after other } \\
\text { measurements and collection of samples were completed. } \\
\text { Sedation was assessed initially by monitoring each dog's } \\
\text { response to opening of the door to the cage, hand clapping, } \\
\text { and speaking to the dog. For pain and distress evaluation, } \\
\text { vocalisation, restlessness, freedom of movement, and } \\
\text { finally, response to firm pressure applied to the region of the } \\
\text { incision were observed. The protocol used was a } \\
\text { modification of scoring systems that are described } \\
\text { elsewhere in literature. }\end{array}$ \\
\hline Study design: & Randomised, blinded, controlled trial \\
\hline Outcome studied: & $\begin{array}{l}\text { - Anaesthetic variables (duration of perioperative sedation, } \\
\text { duration of anaesthesia, mean duration of surgery, and } \\
\text { mean interval from the end of surgery until extubation, } \\
\text { amount of propofol required, end-tidal isoflurane } \\
\text { concentration, } \mathrm{pH} \text { and } \mathrm{SpO}_{2}, \mathrm{PaO}_{2} \text { and } \mathrm{PaCO}_{2} \text {, additional } \\
\text { fluids required, additional propofol and buprenorphine } \\
\text { required to treat excitation during recovery). } \\
\text { - Blood hormone concentrations (concentrations of } \\
\text { epinephrine, norepinephrine, cortisol, and } \beta \text {-Endorphin). } \\
\text { - Heart rate and MAP throughout. } \\
\text { - Assessment of pain and distress (by response to handling, } \\
\text { sedation assessment, pain and distress score via a described } \\
\text { protocol). }\end{array}$ \\
\hline $\begin{array}{l}\text { Main findings: } \\
\text { (relevant to PICO question): }\end{array}$ & $\begin{array}{l}\text { Anaesthetic variables } \\
\text { - Group ACE required significantly more propofol for } \\
\text { induction of anaesthesia (mean of } 3.6 \pm 0.7 \mathrm{mg} / \mathrm{kg} \text { ), } \\
\text { compared with Group MED (mean of } 1.3 \pm 0.2 \mathrm{mg} / \mathrm{kg} \text { ). } \\
\text { - Mean end-tidal isoflurane concentration (ETISO) was } \\
\text { significantly higher during anaesthesia for the Group ACE } \\
\text { (mean of } 1.6 \pm 0.2 \% \text { ), compared with Group MED (mean of } \\
1.4 \pm 0.3 \% \text { ). } \\
\text { - } 11 \text { dogs in Group ACE were given additional fluids (ranging } \\
\text { from 5-10 ml/kg; mean of } 6 \mathrm{ml} / \mathrm{kg} \text { ) at the beginning of } \\
\text { anaesthesia; none of the dogs in the MED group received } \\
\text { any additional fluids. } \\
\text { Blood hormone concentrations } \\
\text { Plasma concentrations of epinephrine and norepinephrine } \\
\text { were significantly lower in Group MED, than Group ACE. The } \\
\text { values for Group MED decreased to a lower concentration } \\
\text { and increased at a later time point than Group ACE also. } \\
\text { Concentration of cortisol was significantly lower for Group } \\
\text { MED, compared with Group ACE; however, the cortisol }\end{array}$ \\
\hline
\end{tabular}




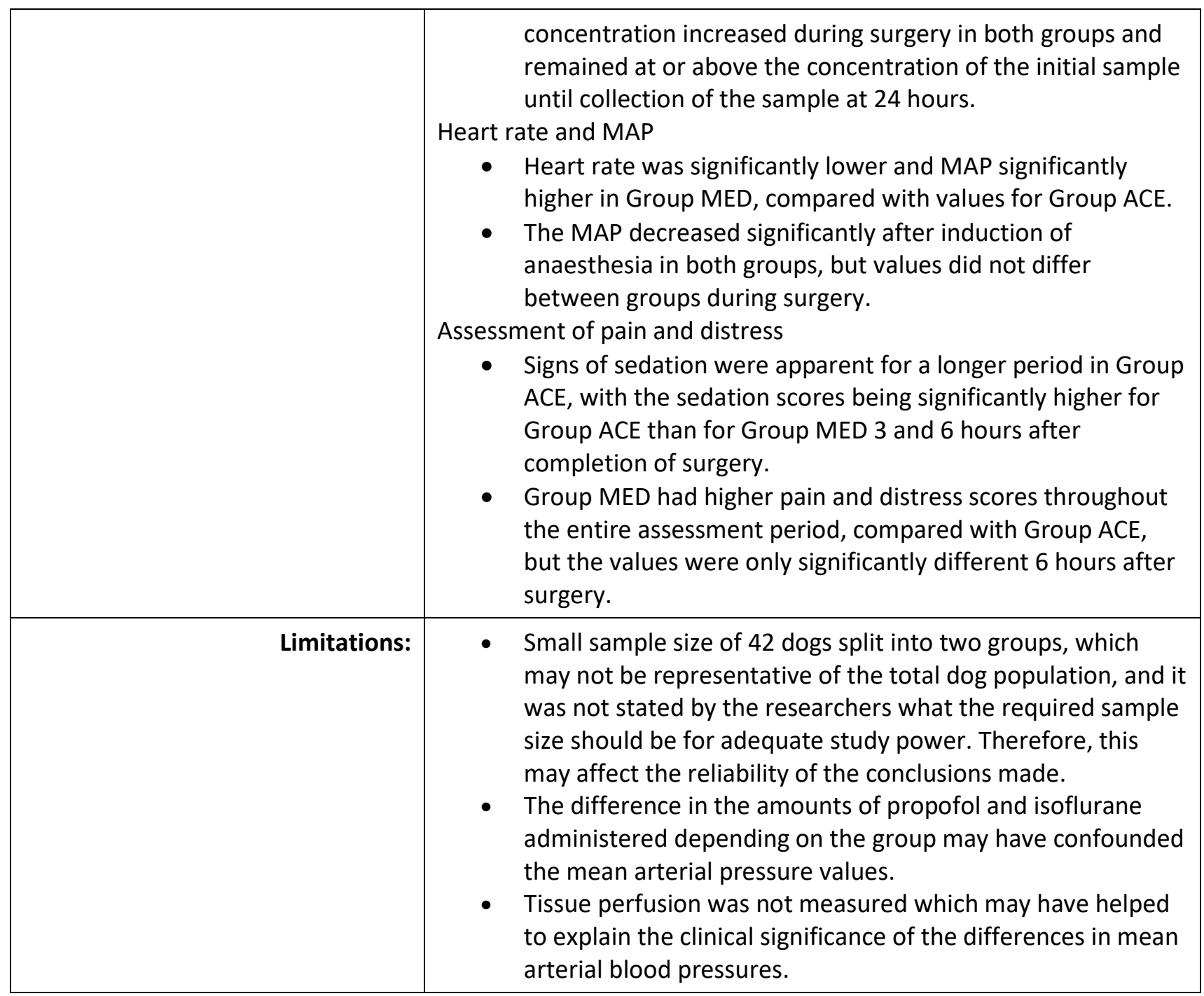

Väisänen et al. (2005)

\begin{tabular}{|c|l|}
\hline Population: & $\begin{array}{l}\text { Dogs that underwent routine elective ovariohysterectomy at } \\
\text { Helsinki University Veterinary Teaching Hospital between January } \\
\text { and August 2000. Inclusion criteria required the dogs to have good } \\
\text { body condition, weigh between } 15 \text { and } 40 \mathrm{~kg} \text {, be } 2-7 \text { years old and } \\
\text { not on any medications. Brachycephalic and Greyhound-type breeds } \\
\text { were excluded. The dogs were determined to be in good health } \\
\text { based on a thorough clinical examination, and haematology and } \\
\text { biochemistry blood analysis. The age and body weights of the dogs } \\
\text { in the two different groups did not differ significantly. }\end{array}$ \\
\hline Sample size: & $\begin{array}{l}\text { 43 dogs (although there were technical errors which led to some } \\
\text { data from both groups not being analysed; this is fully explained in } \\
\text { the results section of the study) }\end{array}$ \\
\hline Intervention details: & $\begin{array}{l}\text { The dogs were randomly allocated to the two treatment } \\
\text { groups by the method of sealed envelopes. } \\
\text { Group MED (21 dogs) were given medetomidine (0.02 } \\
\text { mg/kg) and butorphanol tartrate (0.2 mg/kg), } \\
\text { intramuscularly. }\end{array}$ \\
\hline
\end{tabular}


- Group ACE (22 dogs) were given acepromazine maleate $(0.05 \mathrm{mg} / \mathrm{kg})$ and butorphanol $(0.2 \mathrm{mg} / \mathrm{kg})$, intramuscularly. Experimental procedure

- On the day of the procedures, the dogs arrived at or before noon and stayed in the clinic for 24 hours. On arrival each dog was fitted with an ECG (echocardiogram) Holter monitor and placed in a separate cage in a quiet area and were only handled by the experimental team.

- After around 1 hour of time spent in the cage, the premedication was administered. The dog was then left undisturbed for 15-20 minutes.

- Then a jugular catheter (for blood sample collection) and femoral artery catheter (for continuous direct measurement of blood pressure) were placed whilst the dogs were in lateral or dorsal recumbency with minimal or no restraint. Carprofen ( $4 \mathrm{mg} / \mathrm{kg}$, IV) was administered before induction of anaesthesia.

- Anaesthesia was then induced 85 minutes post premedication, using propofol. Mean \pm SD dosage of propofol was $1.3 \pm 0.2 \mathrm{mg} / \mathrm{kg} \mathrm{IV}$, for dogs premedicated with medetomidine and $3.6 \pm 0.7 \mathrm{mg} / \mathrm{kg} \mathrm{IV}$, for dogs premedicated with acepromazine.

- Anaesthesia was maintained by using isoflurane in oxygen, mean \pm SD (standard deviation) end-tidal isoflurane concentration during anaesthesia was $1.4 \pm 0.3 \%$ for dogs premedicated with medetomidine and $1.6 \pm 0.2 \%$ for dogs premedicated with acepromazine.

- Ovariohysterectomy was performed via a routine standard ventral midline approach by one of three experienced veterinary surgeons.

- During anaesthesia, end-tidal partial pressure of $\mathrm{CO}_{2}\left(\mathrm{ETCO}_{2}\right)$ was maintained at $<60 \mathrm{mmHg}$ by use of intermittent manual ventilation. Oxygen saturation as measured by pulse oximetry remained between $99 \%$ and $100 \%$ and mean arterial blood pressure remained $>60 \mathrm{~mm} \mathrm{Hg}$ throughout surgery in all dogs. Rectal temperature was maintained at $\geq$ $37^{\circ} \mathrm{C}$ by use of heating blankets.

- After finishing the surgery, buprenorphine $(0.010 \mathrm{mg} / \mathrm{kg})$ was administered IV and the duration of preoperative sedation, anaesthesia, and surgery was recorded.

- The dogs recovered in their cages and time until extubation was recorded. Dogs that became excited during recovery were given propofol (2-4 mg/kg, IV) and buprenorphine $(0.005 \mathrm{mg} / \mathrm{kg}$, IV). In seven dogs (two in Group ACE and five in Group MED), an additional dose of buprenorphine (0.01 $\mathrm{mg} / \mathrm{kg}$, IV) was administered 6 hours after surgery. Physical examinations were performed at predetermined time points, and additional warming was provided when needed, to maintain rectal temperature $\geq 37^{\circ}$.

- 6 hours post surgery the dogs were given food and water and taken for a walk. After this, the dogs were taken for walks and physical examinations were performed at 


\begin{tabular}{|c|c|}
\hline & $\begin{array}{l}\text { predetermined intervals. Around } 24 \text { hours after admission, } \\
\text { ambulatory electrocardiography was discontinued, and dogs } \\
\text { were discharged. } \\
\text { The ambulatory electrocardiography equipment used } \\
\text { involved five adhesive electrodes that were used to obtain } \\
\text { two transthoracic leads. To allow an assessment of the } \\
\text { relationship between cardiac activities and perioperative } \\
\text { events, the clock of the Holter monitor was synchronised } \\
\text { with one worn by one of the members of the investigative } \\
\text { team and with the clock on the video recorder used to } \\
\text { record the dogs' behaviour when in their cages. } \\
\text { A standard Holter analysis system was used to analyse } \\
\text { ambulatory ECGs and determine hourly minimum, } \\
\text { maximum, and average heart rates; number of episodes of } \\
\text { second- and third-degree atrioventricular block; number of } \\
\text { ventricular premature complexes (VPCs); and number of } \\
\text { sinus pauses }>2.0 \text { seconds long. To more closely evaluate } \\
\text { heart rate behaviour, printouts of heart rates recorded every } \\
2 \text { minutes were also obtained. Analyses were conducted by } \\
\text { a physician accustomed to reading canine ECGs. Full } \\
\text { disclosure printouts were checked by a veterinarian and } \\
\text { verified by a veterinary cardiologist to ascertain correct } \\
\text { labelling of arrhythmic events. The in-depth methods of ECG } \\
\text { analysis are detailed in full in the study methods. }\end{array}$ \\
\hline Study design: & Randomised controlled trial \\
\hline Outcome studied: & $\begin{array}{l}\text { - } \quad \text { Heart rate } \\
\text { - } \quad \text { Heardiac conduction disturbances } \\
\text { - } \quad \text { Additional observations (lying down time) }\end{array}$ \\
\hline $\begin{array}{l}\text { Main findings: } \\
\text { (relevant to PICO question): }\end{array}$ & $\begin{array}{l}\text { Heart rate } \\
\text { Minimum heart rate during the } 24 \text { hour recording period } \\
\text { was significantly lower among dogs in Group MED (mean of } \\
38 \text { beats/min; } 95 \% \mathrm{Cl}, 35-40 \text { beats/min) than in Group ACE } \\
\text { (mean of } 48 \text { beats/min; } 95 \% \mathrm{Cl}, 45-51 \text { beats/min). This was } \\
\text { mainly attributed to low heart rates during the preoperative } \\
\text { sedation phase and within the first few hours after surgery } \\
\text { in dogs given medetomidine. } \\
\text { Cardiac conduction disturbances } \\
\text { The number of episodes of second-degree atrioventricular } \\
\text { (AV) block was significantly greater among dogs in Group } \\
\text { MED than in Group ACE. In the dogs in Group MED the } \\
\text { episodes of atrioventricular block were mostly in the } 30 \\
\text { minutes following premedication. Both Mobitz type I and II } \\
\text { types of second-degree AV block were seen, but third- } \\
\text { degree atrioventricular block was not identified in any of the } \\
\text { dogs (Kashou et al., 2020). } \\
\text { The number of dogs that had sinus pauses > } 2.0 \text { seconds and } \\
\text { median duration of the longest pauses were significantly } \\
\text { greater among Group MED ( } 20 \text { dogs; median duration of } \\
\text { longest pause, } 3.5 \text { seconds; range, } 2.2-7.5 \text { seconds) than in } \\
\text { Group ACE (14 dogs; median duration of longest pause, } 2.5\end{array}$ \\
\hline
\end{tabular}




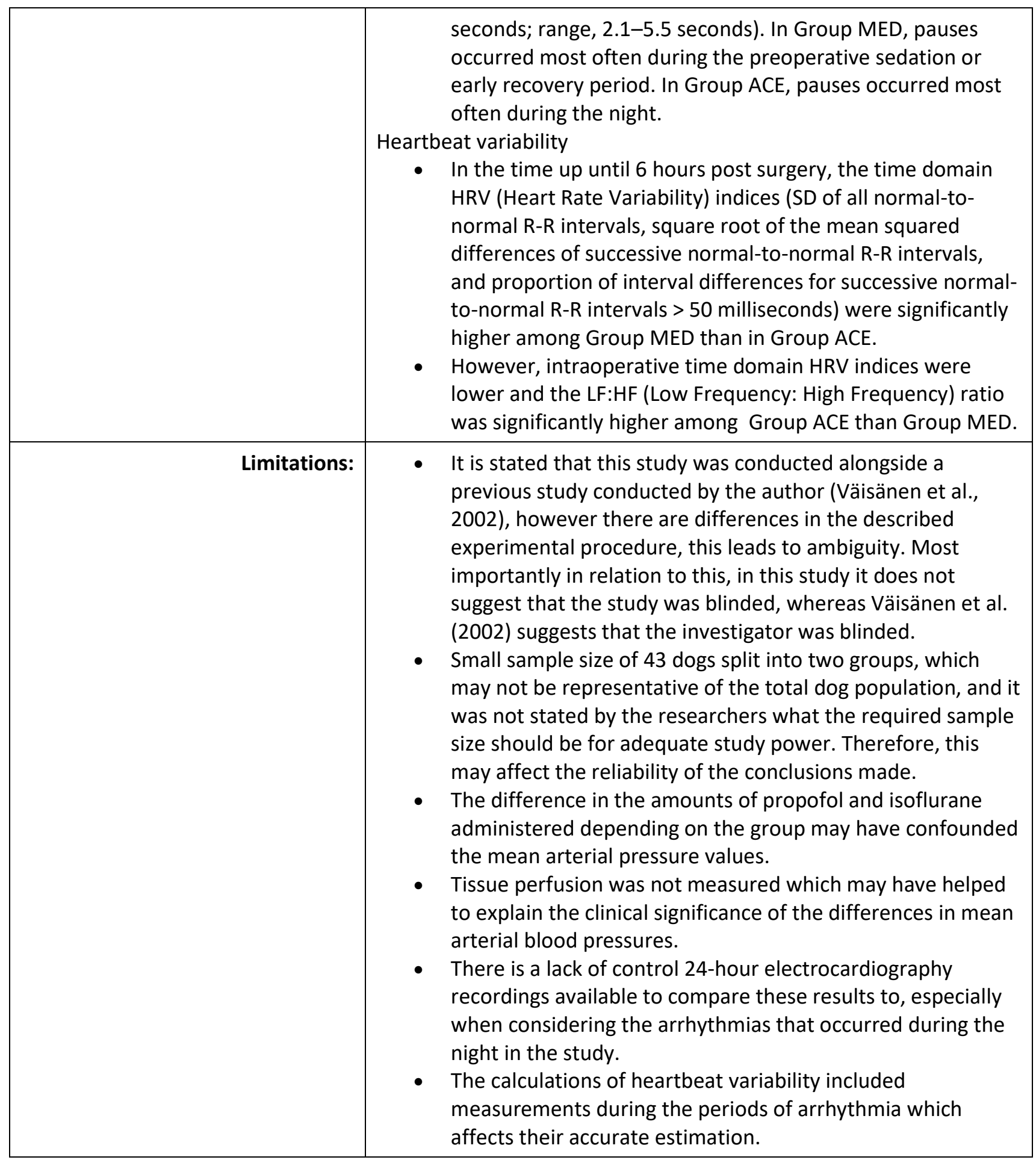

Wamaitha et al. (2019)

\begin{tabular}{|r|l|}
\hline Population: & $\begin{array}{l}\text { Dogs were recruited from willing owners within the area of the } \\
\text { Faculty of Veterinary Medicine, University of Nairobi, Kenya and had } \\
\text { to be free of clinical disease. }\end{array}$ \\
\hline Sample size: & \begin{aligned} 12 male mongrel dogs \\
\hline Intervention details: \end{aligned} \\
\hline $\begin{array}{l}12 \text { dogs split into Group A (six dogs) and Group B (six dogs) } \\
\text { randomly by computer random number generator. }\end{array}$ \\
\hline
\end{tabular}


- Group A involved intramuscular sedation using acepromazine $(0.1 \mathrm{mg} / \mathrm{kg}$ bodyweight) then induction and maintenance of anaesthesia using intravenous $4 \mathrm{mg} / \mathrm{kg}$ ketofol (1:1 ratio of ketamine and propofol).

- Group B involved intramuscular sedation using medetomidine ( $0.02 \mathrm{mg} / \mathrm{kg}$ bodyweight) then induction and maintenance of anaesthesia using intravenous $4 \mathrm{mg} / \mathrm{kg}$ ketofol (1:1 ratio of ketamine and propofol).

Experimental procedure:

- Dogs were housed at the Department of Clinical Studies in individual kennels for 2 weeks of acclimatisation before the study began and were fed a commercial dog food once daily with ad libitum water.

- They were all wormed using a combined praziquantel, pyrantel pamoate, fenbental product (Vermic Total ${ }^{\circledR}$ ) plus given ectoparasite control consisting of chlorfenvinphos (Steladone ${ }^{\circledR}$ ) once per week.

- During this 2-week acclimatisation period the dogs were regularly handled, and clinical examinations performed weekly.

- Food and water were withheld 12 hours prior to the procedure.

- Each dog was weighed using digital scales and sedation and pain scores, pedal and palpebral reflexes were assessed before they were sedated.

- The dogs were then sedated according to whether they were in Group A or B and the investigator was blinded to this process to reduce bias.

- At 10 minutes post sedation, a cephalic intravenous catheter was placed, then the scrotal area was shaved, scrubbed and disinfected with $70 \%$ ethyl alcohol.

- At 30 minutes post sedation, anaesthesia was induced using ketofol and an endotracheal tube was placed.

- The anaesthetic monitoring was supported using a multiparameter machine.

- A standard dose of ketofol ( $50 \%$ of induction dose) was administered when the laryngeal reflex was restored, indicated by coughing. Another dose ( $25 \%$ of induction dose) was drawn up for use if needed throughout the anaesthetic period.

- Orchidectomy was performed routinely, with warmed lactated Ringer's solution administered intravenously through the catheter at $10 \mathrm{ml} / \mathrm{kg} / \mathrm{hr}$ throughout the surgery until extubation.

- The sedation score was measured every 5 minutes from the injection of sedation using a protocol described by Tsai et al. (2013) and were measured for post induction apnoea.

- Palpebral (by running a finger along the dog's eyelashes) and pedal (by firm pressure on interdigital skin of either hindlimb) reflexes were measured throughout the anaesthetic period. 


\begin{tabular}{|c|c|}
\hline & $\begin{array}{l}\text { - The endotracheal tube was removed when the laryngeal } \\
\text { reflex (indicated by coughing) returned and dogs were } \\
\text { monitored in recovery. }\end{array}$ \\
\hline Study design: & Randomised, blinded, controlled trial \\
\hline Outcome studied: & $\begin{array}{l}\text { - Postoperative pain score - assessed using the Short Form } \\
\text { Glasgow Composite Pain Scale (Reid et al., 2007). It was } \\
\text { measured at } 1,2,4,8 \text { and } 24 \text { hours postoperatively. If the } \\
\text { pain score was } \geq 13 \text { out of a total of } 24 \text { at any point, the dog } \\
\text { was excluded from the study and given intramuscular } \\
\text { phenylbutazone at } 8 \mathrm{mg} / \mathrm{kg} \text {. } \\
\text { - Sedation score (using protocol described by Tsai et al., } \\
\text { 2013). } \\
\text { - Duration of anaesthesia. } \\
\text { - Smoothness of recovery- based on number of attempts to } \\
\text { stand and presence of tremors or not. }\end{array}$ \\
\hline $\begin{array}{l}\text { Main findings: } \\
\text { (relevant to PICO question): }\end{array}$ & $\begin{array}{l}\text { Postoperative pain score } \\
\text { - In the second hour postoperatively, dogs in Group A had } \\
\text { significantly ( } p=0.01 \text { ) higher pain scores (median of } 8 \text { ) } \\
\text { compared to dogs in Group B (median of } 6 \text { ). } \\
\text { - In the fourth hour postoperatively, dogs in Group A had } \\
\text { significantly ( } p=0.01 \text { ) higher pain scores (median of } 7 \text { ) } \\
\text { compared to dogs in Group B (median of } 6 \text { ). } \\
\text { - In the eighth hour postoperatively, dogs in Group A } \\
\text { significantly ( } p=0.004 \text { ) higher pain scores (median of } 6.5 \text { ) } \\
\text { compared to dogs in Group B (median of } 4.5 \text { ). } \\
\text { At the end of the monitoring period ( } 24 \text { hours } \\
\text { postoperatively), dogs in Group A had significantly ( } p=0.01 \text { ) } \\
\text { higher pain scores (median of } 5.5 \text { ) compared to dogs in } \\
\text { Group B (median of } 2.5 \text { ). } \\
\text { Smoothness of recovery } \\
\text { Dogs in Group B had a significantly longer ( } p<0.01 \text { ) } \\
\text { extubation time compared to those in Group A. } \\
\text { Dogs in Group A took longer to stand ( } 37.2 \text { minutes } \pm 7 \text { ) than } \\
\text { those in Group B (17 minutes } \pm 7.1 \text { ) which was statistically } \\
\text { significant ( } p=0.04 \text { ). } \\
\text { The pedal reflex was absent for a longer period in the dogs } \\
\text { in Group B (50 minutes) compared to those in Group A (10 } \\
\text { minutes), which was statistically significant ( } p=0.01 \text { ). } \\
\text { The palpebral reflex was absent for a longer period in the } \\
\text { dogs in Group B ( } 30 \text { minutes) compared to those in Group A } \\
\text { (5 minutes), which was statistically significant ( } p=0.04 \text { ). } \\
\text { 83\% (5/6) of dogs in Group A exhibited tremors on recovery } \\
\text { compared to } 33 \% \text { ( } 2 / 6 \text { ) of dogs in Group B. } \\
\text { Cardiorespiratory assessment } \\
\text { apnoea, compared to } 33 \% \text { of dogs given ACP. No individual } \\
\text { numbers of dogs used to calculate these percentages are } \\
\text { stated in the study. }\end{array}$ \\
\hline Limitations: & $\begin{array}{l}\text { - The paper did not analyse any variations in age or weight of } \\
\text { the dogs in the two groups. }\end{array}$ \\
\hline
\end{tabular}




\begin{tabular}{|l|l|}
\hline - & Small sample size of 12 dogs split into two groups, which \\
may not be representative of the total dog population, and it \\
was not stated by the researchers what the required sample \\
size should be for adequate study power. Therefore, this \\
may affect the reliability of the conclusions made. \\
- \\
No values given for extubation time for both treatment \\
groups. \\
No evaluation of cardiorespiratory parameters pre, peri or \\
postoperatively. \\
Many of the comparisons of values that show differences in \\
outcomes are not statistically significant. \\
Some outcomes have percentages given but it is not \\
specified as whether they were found to be statistically \\
significant or not. \\
The pain score cut off used for rescue analgesia in this study \\
was greater than or equal to 13/24, whereas in clinical \\
practice a much lower cut off may be used. \\
It is not clear whether the investigator conducting the \\
observations/pain scores was consistent throughout, or \\
whether there were multiple observers as this could lead to \\
inconsistent assessment of the dogs.
\end{tabular}

\section{Appraisal, application and reflection}

When appraising the evidence on this topic it became clear that there were only four papers that directly compare the use of medetomidine and acepromazine in a randomised control trial study design. Any other study design was deemed not relevant to the PICO question as studies with different intervention protocols cannot be directly compared. It is also important to consider what is defined as an 'anaesthetic complication', as this may vary based on different studies. According to one study looking into the incidence of cardiorespiratory anaesthetic complications, (in descending order of incidence) bradycardia, hypotension, hypoventilation, hypoxia, hypothermia and death were the most common (Redondo et al., 2007). A rapid, smooth and complete recovery is advantageous in veterinary patients, especially in outpatient procedures such as neutering (Laing et al., 2009). An important aspect of this is peri and postoperative pain which can contribute to a poor recovery, and cardiorespiratory complications also occur in recovery (Lerche et al, 2000).

In the first study evaluated (Grint et al., 2010) it was shown that medetomidine maintained blood pressure better than acepromazine, but whether this has any clinical benefit was not studied. This could have potentially been assessed by measuring tissue perfusion which was not done in the study and would have improved the clinical relevance. However, the practicalities of this would be difficult in a clinical setting with there being no readily available clinical equipment to measure this or available normal values for comparison; and it would have to be determined which tissue or tissues were relevant to study. It was also found that mean and lowest heart rates perioperatively were significantly higher for dogs given acepromazine, compared to those given medetomidine, which may be because acepromazine has no analgesic properties (Thurmon et al., 1996; and Smith et al., 2001). This may also be due to alpha-2 adrenergic receptor agonist drugs such as medetomidine often causing a decrease in heart rate of patients due to its pharmacological effects on blood pressure (Murrell, 2016). Overall, the study had strong methodology due to the randomised controlled trial design with a large sample size and had minimal limitations because of this, therefore the results are highly applicable to the overall dog population. However, the study did not fully explain the clinical conditions of the dogs who were judged to have an ASA status of 2 (mild systemic disease) but this may have had a confounding effect on the outcomes (Abouleish et al., 2015). There were also differences in the amounts of propofol and isoflurane administered between the groups which could have confounded the mean arterial pressure values 
as propofol has hypotensive effects due to resetting of baroreceptor sensitivity so reflex tachycardia often does not occur (Grood et al., 1987) plus isoflurane causes dose-dependent cardiovascular depression and a reduction of blood pressure (Lynch, 1986).

In the second study evaluated (Väisänen et al. (2002), it was found that plasma concentrations of epinephrine, norepinephrine and cortisol levels were significantly lower in the group receiving medetomidine than those given acepromazine. This would suggest that medetomidine elicits a reduced perioperative stress response when administered compared to acepromazine, however the medetomidine group did have significantly higher pain and distress scores than the acepromazine group 6 hours post surgery. It is proposed that an increased stress response could be a factor in patient morbidity during anaesthesia (Desborough, 2000), so this study suggests that medetomidine would be better as reducing this risk. A limitation of this study was the sample size; by using only 42 dogs split into the two groups, it may not be representative of the normal dog population. It was also not stated by the researchers if any statistical power calculations were carried out in order to work out an adequate sample size to use. It is also worth noting that the authors used either acepromazine or medetomidine in combination with butorphanol as the premedication in the study; butorphanol is a opioid with only mild analgesic effects at the doses given in the study (Grimm et al., 2000). Therefore, acepromazine and butorphanol as a premedication would provide very little analgesia to the patient. Due to this, opioids with more potent analgesic properties should ideally be used for surgical procedures, such as methadone or buprenorphine. It has been suggested by research that pre-emptive analgesia is much more effective than giving peri or postoperative analgesia like this study did (Dahl et al., 2005). This may have affected the results, as having more appropriate increased analgesia may have had a differing effect on the variables measured, especially heart rate.

In the third study evaluated (Väisänen et al. (2005), it was found that heart rates were significantly lower during the 24-hour monitoring period for those dogs administered medetomidine compared to those given acepromazine, however this is not surprising given the pharmacological effects of medetomidine as alpha2agonists often cause bradycardia due to their effects on blood pressure (Murrell, 2016). In those given medetomidine, there were significantly greater number of episodes of second-degree atrioventricular block compared to those given acepromazine, and mostly these were in the 30 minutes after premedication, which suggests medetomidine may be the cause. The medetomidine group also had a significantly greater number of dogs with sinus pauses greater than 2 seconds and the median duration of the longest were also significantly longer. It is also important to recognise that the methods that the study used to calculate heartbeat variability values can be affected by unstable experimental conditions, which would have unavoidably happened in this study as the patients were left unattended, especially overnight. Overall, the study does provide data on the cardiac electrical activity and autonomic modulation in dogs undergoing routine surgery when acepromazine or medetomidine is used as part of a premedication, and showed that greater influences on cardiac efferent vagal activities were documented for dogs premedicated with medetomidine than with acepromazine. The clinical importance of this is currently unknown, and further research on this relevance should be conducted.

In the fourth study evaluated (Wamaitha et al., 2019), at four of the five time points when postoperative pain was assessed by pain scoring, the dogs given acepromazine had statistically significantly higher pain scores than those given medetomidine. Again, acepromazine has no analgesic effects (Thurmon et al., 1996; and Smith et al., 2001) which could explain these differences. It may also be important to consider the pain score cut off that studies use for rescue analgesia, as in this study the dogs were given additional analgesia if the pain score was greater than or equal to $13 / 24$, whereas in clinical practice a much lower cut off may be used. The short-form Glasgow Composite Measure Pain Scale (CMPS-SF) is commonly used to pain score animals in clinical practice, as it is a shortened version of the highly validated Glasgow Composite Measure Pain Scale. The clinical intervention point for additional analgesia is $6 / 24$ in the CMPS-SF (Reid et al., 2007), so is considerably lower than the cut off used in this study. This suggests that many more of the dogs in the study may have required additional analgesia if the CMPS-SF cut off value was used to pain score the dogs, and raises potential welfare concerns. The paper also does not report the distribution of the pain score data and presents the median as decimals when the score is an integer. The study reports that the dogs given 
medetomidine had a smoother recovery based on the finding that dogs given medetomidine took significantly less time to stand, appeared to struggle less and exhibited less tremors on recovery. However, the extubation time was significantly longer than those given acepromazine along with fewer attempts to stand, plus the pedal and palpebral reflexes were absent for longer than those given acepromazine. It is not clear whether the investigator conducting the observations/pain scores was consistent throughout, or whether there were multiple observers as this could lead to inconsistent assessment of the dogs, plus some of the outcomes such as 'appearing to struggle less' are subjective measures.

A key limitation of this study was the sample size; by using only 12dogs split into the two groups, it may not be representative of the normal dog population. It was also not stated by the researchers if any statistical power calculations were carried out in order to work out an adequate sample size to use. Therefore, this may have affected the reliability of the conclusions based on the statistical significance values suggested by the researchers. The researchers also did not analyse any variations in age or weight of the dogs between those allocated to the two different groups and this could have led to individual differences in the dogs confounding the outcome results.

Another limitation of the study is that no evaluation of cardiorespiratory parameters especially perioperatively such as blood pressure, heart rate etc. was performed. These are important measures of potential anaesthetic complications and should have been monitored as part of routine anaesthetic monitoring by the researchers so could have been stated and analysed in the study.

The use of ketofol (ketamine mixed with propofol) is not commonly used in the UK veterinary industry as an induction agent in dogs in combination with propofol, however the use of ketamine in combination induction protocols is routinely used. This induction using ketamine could explain the incidence of muscle tremors during recovery, as ketamine is known to cause muscle tremors, increased muscle tone and spontaneous movement in dogs (Kovalcuka et al., 2013). Alfaxalone is also commonly used as an induction agent in the UK and none of the papers found had evaluated this drug in any of their protocols which could be an area of future research. The study suggested that the reason that the dogs receiving acepromazine exhibited more muscle tremors than those given medetomidine was due to the medetomidine causing muscle relaxation, whereas the acepromazine is not as effective at counteracting the muscle effects of ketamine. Therefore, as ketamine is not often used by vets as a co-induction agent, muscle tremors are less likely to occur in recovery anyway so the clinical benefits of using medetomidine to reduce these may not be relevant. It is also important to consider that the premedication used involved a single drug (acepromazine or medetomidine), whereas in general veterinary practice in the UK a combination using an opioid agent alongside the sedative agent is often used. This sedative and opioid combination may have potentially led to less side effects, than using the sedative agent alone with a ketofol induction.

All of the studies appraised showed some statistically significant differences between using medetomidine and acepromazine as premedications in the outcomes measured, but as the clinical parameters such as blood pressure still were within acceptable clinical limits, the clinical benefits of these findings remain undetermined. There is also evidence to suggest that patients premedicated with medetomidine have less of a perioperative stress response than those receiving acepromazine, but may have increased risk of cardiac conduction disturbances, but the clinical importance of these findings is also unknown. The overall findings showed that either drug can be used as a suitable premedication. However, the differences in pain score postoperatively shown in the small Wamaitha et al. study (2019) and due to its poor analgesic properties, it is suggested that when using acepromazine additional analgesia should be given to reduce postoperative pain for better animal welfare. Another key point to consider is that human error is the most common causes of problems during anaesthetic monitoring (Egger, 2016), therefore being vigilant when monitoring through the anaesthetic period is of paramount importance. To reduce complications, irrespective of the drugs used to premedicate dogs, the patient should be adequately stabilised before beginning procedures and attentive perioperative and postoperative monitoring is vital. It is also important to consider the patients as individuals and adapt 
anaesthetic protocols to their individual status, to avoid inaccurate drug doses, and to have protocols in place for when complications do arise.

\section{Methodology Section}

\begin{tabular}{|c|c|}
\hline \multicolumn{2}{|l|}{ Search Strategy } \\
\hline $\begin{array}{r}\text { Databases searched and dates } \\
\text { covered: }\end{array}$ & $\begin{array}{l}\text { CAB Abstract } 1973-23^{\text {rd }} \text { April } 2020 \\
\text { PubMed (NCBI) } 1973-2020 \\
\text { Web of Science } 1900-2020\end{array}$ \\
\hline Search terms: & $\begin{array}{l}\text { This search strategy was used in all databases: } \\
\text { (elective OR routine OR anesthetized OR anaesthetized OR } \\
\text { anesthetized OR anaesthetised OR anaesthesia OR anesthesia OR } \\
\text { anaesthetic OR anesthetic OR pre-medication OR premedication OR } \\
\text { pre-anaesthetic OR pre-anesthetic OR preanaesthetic OR } \\
\text { preanesthetic) and (dog OR dogs OR bitch* OR canine OR canines) } \\
\text { AND (acp OR acepromazine and medetomidine) }\end{array}$ \\
\hline Dates searches performed: & 23 Apr 2020 \\
\hline
\end{tabular}

Exclusion / Inclusion Criteria

Exclusion: Articles not available in English, unsuitable paper types including book chapters, single case reports conference proceedings, irrelevant to the PICO question, inaccessible articles.

Inclusion: Any relevant research relating to the PICO question.

\begin{tabular}{|c|c|c|c|c|c|c|}
\hline \multicolumn{7}{|c|}{ Search Outcome } \\
\hline Database & $\begin{array}{c}\text { Number } \\
\text { of } \\
\text { results }\end{array}$ & $\begin{array}{l}\text { Excluded - } \\
\text { [not } \\
\text { available } \\
\text { in English } \\
\text { language] }\end{array}$ & $\begin{array}{c}\text { Excluded - [case } \\
\text { report/book } \\
\text { chapter/irrelevant } \\
\text { paper type] }\end{array}$ & $\begin{array}{c}\text { Excluded - } \\
\text { [irrelevant to } \\
\text { PICO question] }\end{array}$ & $\begin{array}{l}\text { Excluded - } \\
\text { [duplicate } \\
\text { article] }\end{array}$ & $\begin{array}{l}\text { Total } \\
\text { relevant } \\
\text { papers }\end{array}$ \\
\hline $\begin{array}{l}\text { CAB } \\
\text { Abstracts }\end{array}$ & 62 & 5 & 8 & 45 & 0 & 4 \\
\hline PubMed & 38 & 0 & 0 & 34 & 0 & 4 \\
\hline $\begin{array}{l}\text { Web of } \\
\text { Science }\end{array}$ & 119 & 7 & 1 & 106 & 1 & 4 \\
\hline Total relev & nerc & duplicat & noved & & & 4 \\
\hline
\end{tabular}


The author declares no conflicts of interest.

\section{REFERENCES}

1. Abouleish, A.E., Leib, M.L. and Cohen, N.H. (2015). ASA Provides Examples to Each ASA Physical Status Class. ASA Newsletter. 79, 38-49.

2. Dahl, J.B. and Møiniche S. (2005). Pre-emptive analgesia. British Medical Bulletin. 71(1), 13-27.

DOI: https://doi.org/10.1093/bmb/ldh030

3. Desborough, J.P. (2000). The stress response to trauma and surgery. British Journal of Anaesthesia. 85, 109-117. DOI: https://doi.org/10.1093/bja/85.1.109

4. Egger, C.M. (2016). BSAVA manual of canine and feline anaesthesia and analgesia. British Small Animal Veterinary Association (BSAVA Manuals Series).

5. Grimm, K.A., Tranquilli, W.J., Thurmon, J.C. and Benson, G.J. (2000). Duration of nonresponse to noxious stimulation after intramuscular administration of butorphanol, medetomidine, or a butorphanol-medetomidine combination during isoflurane administration in dogs. American Journal of Veterinary Research. 61(1), 42-7. DOI: https://doi.org/10.2460/ajvr.2000.61.42

6. Grint, N.J., Alderson, B. and Dugdale, A.H. (2010). A comparison of acepromazine-buprenorphine and medetomidine-buprenorphine for preanesthetic medication of dogs. Journal of the American Veterinary Medical Association. 237(12), 1431-7. DOI: http://dx.doi.org/10.2460/javma.237.12.1431

7. Grood, P.M.R.M.D., Coenen, L.G.J., Egmond, J.V., Booij, L.H.D.J. and Crul, J.F. (1987). Propofol emulsion for induction and maintenance of anaesthesia. A combined technique of general and regional anaesthesia. Acta Anaesthesiologica Scandinavica, 31(3), 219-223.

DOI: http://dx.doi.org/10.1111/j.1399-6576.1987.tb02554.x

8. Kashou, A.H., Goyal, A., Nguyen, T. and Chhabra, L. (2020). Atrioventricular Block. StatPearls Publishing.

9. Kovalcuka, L., Birgele, E., Bandere, D. and Williams, D.L. (2013). The effects of ketamine hydrochloride and diazepam on the intraocular pressure and pupil diameter of the dog's eye. Veterinary Ophthalmology. 16(1), 29-34. DOI: https://doi.org/10.1111/i.1463-5224.2012.01015.x

10. Laing, S., Paul, V. and Murison, P.J. (2009). The effects of nitrous oxide on recovery from isoflurane anaesthesia in dogs. Journal of Small Animal Practice. 50(2), 82-86.

DOI: https://doi.org/10.1111/i.1748-5827.2008.00689.x

11. Lerche, P., Reid, J. and Nolan, AM. (2000). Comparative study of propofol or propofol and ketamine for the induction of anaesthesia in dogs. Veterinary Record. 146, 571-574.

DOI: http://dx.doi.org/10.1136/vr.146.20.571

12. Lynch, C. (1986). Differential depression of myocardial contractility by halothane and isoflurane in vitro. Anesthesiology. 64, 620-631. DOI: http://dx.doi.org/10.1097/00000542-198605000-00013

13. Murrell, J.C. (2016). BSAVA manual of canine and feline anaesthesia and analgesia. British Small Animal Veterinary Association (BSAVA Manuals Series).

14. Redondo, J.I., Rubio, M., Soler, G., Serra, I., Soler, C. and Gómez-Villamandos, R.J. (2007). Normal Values and Incidence of Cardiorespiratory Complications in Dogs During General Anaesthesia. A Review of 1281 Cases. Journal of Veterinary Medicine Series A. 54(9), 470-477.

DOI: https://doi.org/10.1111/i.1439-0442.2007.00987.x

15. Reid, J., Nolan, A., Hughes, J., Lascelles, D., Pawson, P. and Scott, E. (2007). Development of the shortform Glasgow Composite Measure Pain Scale (CMPS-SF) and derivation of an analgesic intervention score. Animal Welfare. 16, 97-104. 
16. Smith, L.J., Yu, J.K., Bjorling, D.E. and Waller, K. (2001). Effects of hydromorphone or oxymorphone, with or without acepromazine, on preanesthetic sedation, physiologic values, and histamine release in dogs. Journal of the American Veterinary Medical Association. 218, 1101-1105.

DOI: https://doi.org/10.2460/iavma.2001.218.1101

17. Thurmon, J.C., Tranquilli, W.J. and Benson, G.J. (1996). Preanesthetics and anesthetics adjuncts. Veterinary Anesthesia (3rd ed.). Thurmon JC, Tranquilli WJ, Benson GJ (eds). Williams \& Wilkins, Baltimore, USA, pp. 183-189.

18. Tsai, T.Y., Chang, S.K., Chon, P.Y., Yeh, L.S. (2013). Comparison of postoperative effects between lidocaine infusion, meloxicam and their combination in dogs undergoing ovariohysterectomy. Veterinary Anaesthesia Analgesia. 40, 615-

22. DOI: https://doi.org/10.1111/vaa.12064

19. Väisänen, M., Raekallio, M., Kuusela, E., Huttunen, P., Leppäluoto, J., Kirves P. and Vainio, O. (2002). Evaluation of the perioperative stress response in dogs administered medetomidine or acepromazine as part of the preanesthetic medication. American Journal of Veterinary Research. 63(7), 969-975. DOI: https://doi.org/10.2460/ajvr.2002.63.969

20. Väisänen, M., Vainio, O., Raekallio, M., Hietanen, H., and Huikuri, H. (2005). Results of 24-hour ambulatory electrocardiography in dogs undergoing ovariohysterectomy following premedication with medetomidine or acepromazine. Journal of the American Veterinary Medical Association. 226(5), 738745. DOI: https://doi.org/10.2460/javma.2005.226.738

21. Wamaitha, M.N., Mogoa, E.M. and Mande, J.D. (2019). Evaluation of anesthesia produced by ketofol in acepromazine- or medetomidine-sedated dogs. Journal of advanced veterinary and animal research. 6(2), 215-221. DOI: http://doi.org/10.5455/javar.2019.f335 


\section{EVIIDEFeE

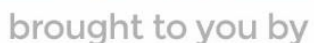 \\ RCVS KNOWLEDGE}

\section{Intellectual Property Rights}

Authors of Knowledge Summaries submitted to RCVS Knowledge for publication will retain copyright in their work, and will be required to grant RCVS Knowledge a non-exclusive license of the rights of copyright in the materials including but not limited to the right to publish, re-

publish, transmit, sell, distribute and otherwise use the materials in all languages and all media throughout the world, and to license or permit others to do so.

\section{Disclaimer}

Knowledge Summaries are a peer-reviewed article type which aims to answer a clinical question based on the best available current evidence. It does not override the responsibility

of the practitioner. Informed decisions should be made by considering such factors as individual clinical expertise and judgement along with patient's circumstances and owners' values. Knowledge Summaries are a resource to help inform and any opinions expressed within the Knowledge Summaries are the author's own and do not necessarily reflect the view of the RCVS Knowledge. Authors are responsible for the accuracy of the content. While the

Editor and Publisher believe that all content herein are in accord with current recommendations and practice at the time of publication, they accept no legal responsibility

for any errors or omissions, and make no warranty, express or implied, with respect to material contained within.

For further information please refer to our Terms of Use.

RCVS Knowledge is the independent charity associated with the Royal College of Veterinary Surgeons (RCVS). Our ambition is to become a global intermediary for evidence based veterinary knowledge by providing access to information

that is of immediate value to practicing veterinary professionals and directly contributes to evidence based clinical decision-making.

\section{https://www.veterinaryevidence.org/}

RCVS Knowledge is a registered Charity No. 230886.

Registered as a Company limited by guarantee in England and Wales No. 598443.

Registered Office: Belgravia House, 62-64 Horseferry Road, London SW1P 2AF

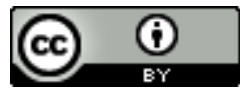

This work is licensed under a Creative Commons Attribution 4.0 International License 